\title{
VOLVIENDO A LAS HISTORIAS DE LOS CIENTÍFICOS
}

\section{RETURNING TO THE STORIES OF SCIENTISTS}

José Antonio Martínez Pons: Departamento de Química Analítica e Ingeniería Química. Universidad de Alcalá de Henares. Madrid (España) joseantonio.martines@uah.es

\section{CURRÍCULUM VITAE}

Licenciado en Ciencias Físicas (Geofísica) por la Universidad Complutense de Madrid (España) y en Ciencias Químicas (Química física) por la UNED (España). Doctor por la Universidad de Alcalá de Henares (España) en el año 2000. Profesor de la Universidad de Alcalá de Henares en el área de Química analítica e Ingeniería química.

\section{RESUMEN}

Desde hace bastante tiempo, en la comunidad científica existen las grandes disputas sobre la paternidad de los descubrimientos. Siempre hay prisa por publicar y los plagios, igualmente, se producen. En la Edad Media no ocurría así, importaban las obras, no los autores.

\section{PALABRAS CLAVE}

Comunidad científica - Obra - Autor 


\begin{abstract}
For some time, in the scientific community there are major disputes about the paternity of the findings. There is always a rush to publish and plagiarism, also occur. In the Middle Ages was not the case, imported works, not authors.
\end{abstract}

\title{
KEY WORDS
}

Scientific community - Work - Author

\section{TEXTO:}

Hoy día, y desde hace bastante tiempo, en la comunidad científica existen las grandes disputas sobre la paternidad de tal o cual descubrimiento, la prisa por publicar, para que no levanten a uno la liebre es causa de más de un pequeño desastre y, nos guste o no, el plagio, con los nombre piadosos que se nos ocurran, está ahí. Una vez escuché comentar a una personalidad científica ya al final de su carrera que sólo en dos mundos se dan más zancadillas y puñaladas que en el mundo académico de gran altura: en el de los divos de la ópera y en el de los atletas de élite. Son esos mundos en donde se deja corto a Don Quijote cuando dice aquello "Poderoso es el nombre de primero". Como servidor no pasa de ser un mero figurante del coro en este mundillo, se limita a observar y, más de una vez, a sonreír al ver como personas, de presunto gran nivel, se comportan como niños envidiosos y mezquinos, en tocando sus parcelitas, pero dejemos el presente. ¿Siempre fue así?

Si y no. 
En la Edad Media e incluso después, la autoría no era tan importante, lo importante era que las obras de uno se publicaran y fueran conocidas, y esto en todos los campos, ¿Se sabe el nombre de los autores de la mayoría de maravillosas miniaturas que ornan los códices medievales o de las magnas obras del canto gregoriano? El autor no importaba, importaba la obra. Así era también, en el mundo de la ciencia, entendida como se entendía entonces; y no me voy a meter, al menos hoy, en el tema, pero empieza a ser hora de que se desmonte el tópico del oscurantismo de la Edad Media, que no es cierto. Era normal que, cuando alguien escribía algo que creía debía ser conocido y estudiado, atribuyera la paternidad a un autor de fama reconocida, valga por ejemplo el caso del mallorquín Ramón Llull (1233 ó 1235 - 1315). Muchas de las obras que se le atribuyen son espurias, especialmente las de alquimia. El "Doctor iluminado" no solamente no fue alquimista sino que, en más de una de sus obras auténticas, se manifiesta claramente en contra del arte alquímico. No obstante, hasta Julio Verne en pleno siglo XIX, y sabido es lo bien que se documentaba el francés, le reconoce como maestro alquimista, ha sido la crítica actual la que ha expurgado muchas de las obras a él atribuidas.

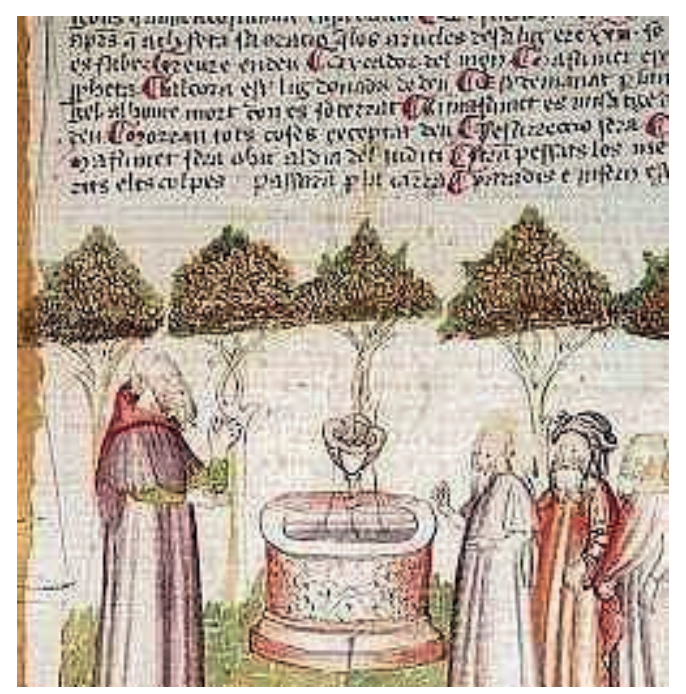

Miniatura en una obra de Ramón Llull 
Algo parecido ocurre con "Aubertus Magnus", "Albert der Grosse" o San Alberto el Grande, primer alemán que enseñó en la Sorbona y maestro de santo Tomás de Aquino, hoy reconocido patrón de la ciencia. Tampoco era ajeno a esta situación el miedo de los autores a publicar tesis que pudieran considerarse contrarias a la doctrina religiosa en vigor, insisto, no solamente "católicas" (si malo es el "fundamentalismo" religioso, peor es el fundamentalismo "laico", "antirreligioso" o "anticatólico").

Otro caso curioso, ya bien cumplida la Edad Media es el Johan Daniel Dietz, también conocido como Titius de Wittemberg (1729-1796). Este oscuro profesor de matemáticas y astronomía de Wittemberg descubrió que la distancia de los seis planetas conocidos al Sol medidas en unidades astronómicas seguía la siguiente ecuación

$\mathrm{a}=0,4+0,3 * 2 \mathrm{n}-1$

Donde $\mathrm{n}$ es el número de orden del planeta, empezando por Mercurio, y con la salvedad de que, al llegar a Júpiter, hay que saltarse un puesto, el 5, y pasar del 4, Marte al 6 Júpiter. (Precisamente en este puesto se encontró Ceres, un asteroide particularmente "grande", al parecer se descubrió gracias a la ley de Titius - Bode). Titius no la publicó como suya, sino que la incrustó en la traducción de un libro sobre la inspiración divina en la Naturaleza.

Charles Bonnet (1720-1793) era un naturalista suizo que entre otras cosas, había estudiado la partenogénesis de los pulgones, pero con unas ideas filosóficas un tanto 
pintorescas. Bonnet había publicado un libro, "Contemplación de la Naturaleza", en el que dejaba su visión personal sobre la importante conexión entre los dioses y la Naturaleza. Titius hizo de traductor de la obra e introdujo su ley en ella, publicando el libro en 1772. Parece que ésta no fue la única "morcilla" que incrustó. El libro se olvidó durante un tiempo, hasta que un astrónomo alemán, Johann Elert Bode (17471826), que había fundado en 1774 el Anuario Astronómico Berlinés, la dio a conocer (de nuevo) en 1778, en una introducción a la Astronomía, escrita por él mismo. Bode no mencionó para nada el origen real de la ley (pese a que la había leído en la traducción realizada por Titius del libro de Bonnet) y todo el mundo creyó que era Bode su auténtico descubridor. En ediciones posteriores de su obra no tuvo más remedio que aceptar la procedencia de la ley, a su pesar. De hecho, Bode continuó citándola en sus escritos simplemente como "ley de Bode", por lo que los eruditos de la época -e incluso hasta en la actualidad puede encontrarse en muchas publicaciones prestigiosas- la llamaban así, olvidándose por completo del auténtico creador.

Pero ya en esta época empezaban los problemas de "paternidad intelectual". Todavía no en las artes, donde el plagio era común, incluso aceptado como un honor si el plagiado se consideraba de menos talla que el plagiador, valga el ejemplo de la inclusión por W.A. Mozart de un fragmento del la ópera "Una cosa rara" del valenciano Vicente Martín y Soler (Vinzenzo lo spagnuolo) en su Don Giovanni. Algún autor hasta se plagiaba a si mismo, como el gran G.F. Haendel. Por supuesto "reciclar" trabajos anteriores lo hacía hasta J.S.Bach. No existía el desacerbado deseo actual de pasar a la posteridad. También J.S. Bach durmió una buena temporada el sueño de los justos, hasta que Félix Mendelson le redescubrió para gozo y disfrute de quienes tengan un mínimo se sentido musical. Hoy día, en el mundo científico, la churrera y la rebanadora de chorizos en lonchas bien finas están a la orden del día, y tanto publicas, tanto vales, en consecuencia, si se tiene una buena idea, se trata de sacarle el máximo rendimiento posible, siempre en términos de papel impreso. Claro 
que siempre hay excepciones como Henry Cavendish (1731-1810) pintoresco físico y químico inglés, insociable hasta el límite, que sentía terror ante las mujeres, hasta el extremo de comunicarse con sus sirvientas por notas escritas y que, no obstante, en una vida de intenso y variado trabajo sólo publicó veinte artículos y ningún libro. Su ambición era saber, no ejercer de sabio. Quién sabe la cantidad de descubrimientos que se llevó a la tumba...

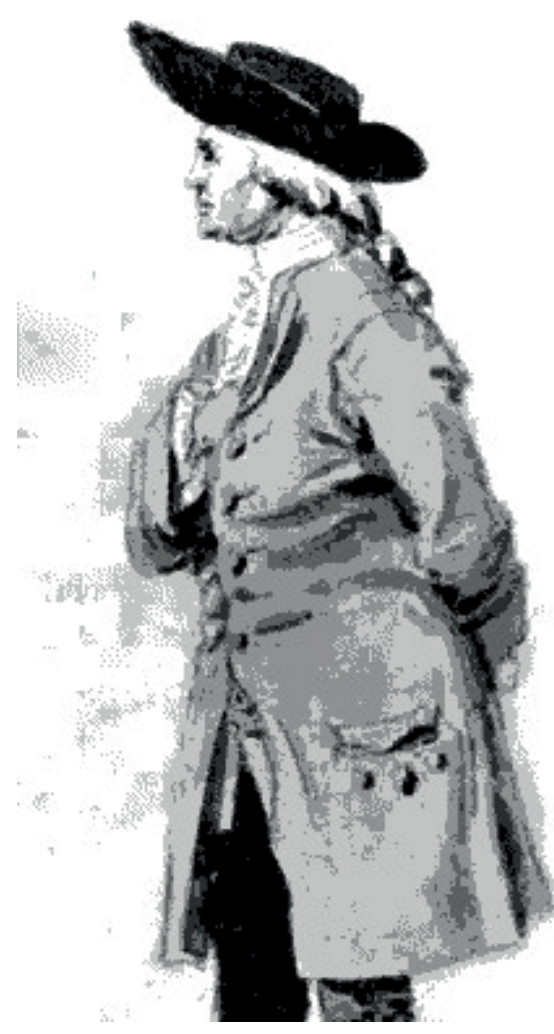

Única imagen conocida de Henry Cavendish y de exactitud bastante dudosa

Siguiendo con el tema científico, hasta hace poco la única fuerza de que se disponía era la fuerza de sangre, por esto los ayudantes de laboratorio de los "científicos" solían ser personas fuertes y no demasiado listas. Se cuenta de Robert Boyle (16271691) que un día, mientras sus ayudantes trabajan en el laboratorio, él estaba con sus amigos en la "rebotica", en amigable discusión sobre todo lo divino y lo humano. De repente, en el laboratorio, se organizó un gran alboroto. Había estallado una caldera 
o algo semejante. Los ilustres caballeros acudieron con presteza. La ropa de uno de los laborantes ardía. Boyle se apresuró a socorrerle.

- Miren ustedes si soy bueno, -contaba Boyle al día siguiente,- que apagué las llamas del desgraciado, le puse ungüento en las quemaduras, me manché mi mejor casaca, vi arruinado el experimento y no le despedí.

Bueno, pues uno de los ayudantes de tan benévolo y generoso personaje, salió listo y decidió independizarse, de modo que dejó el laboratorio de Boyle y montó el suyo propio. El díscolo en cuestión dio en publicar algunas investigaciones que había realizado. Boyle ató cabos y calculó que el trabajo básico lo había hecho cuando aún estaba a su servicio y, ni corto ni perezoso, le demandó por plagio ya que todo lo que en su laboratorio se hacía para él se hacía. (¿Hace falta retroceder 350 años para encontrarnos con situaciones semejantes?, al observador lector dejo la respuesta).

Por cierto no dije el nombre del prófugo plagiario, era Robert Hooke (1635-1703) el "enano" que no gigante de Newton, quien había entrado al servicio de Boyle recomendado por el químico Tomás Willis y le había ayudado en la construcción de una bomba de aire.

Y siguiendo con Hooke y Newton. Sir Isaac también tuvo sus problemas con el bueno de Leibniz sobre todo por la paternidad del cálculo infinitesimal, o teoría de fluxiones, como la llamaba el escocés. Las reivindicaciones las teledirigía Newton a través de Samuel Clarke, un discípulo suyo e importante filósofo en aquel momento, hoy sus ideas están casi olvidadas. Éste recurría a argumentos como tomar un texto de Newton escrito en latín, por supuesto, y fechado antes que el escrito de Leibniz, reorganizaba el texto y lo recomponía para que dijera lo mismo que el alemán pero antes. Realmente la técnica de escribir en clave era corriente y al parecer la utilizó ya Leonardo. Leibniz hasta se lo creía y en algún documento suyo aparece algo como, 
"yo creí haber descubierto esto pero mi eminente colega el escocés Isaac Newton, lo había descubierto antes que yo". Las peloteras entre Clarke y Leibniz también se referían a las concepciones filosóficas de ambos pensadores, pero éste es otro tema. Y ya que andamos con Newton. Era terriblemente tímido, quizá por esto mismo tenía un carácter tan agrio y egoísta. Cuando le nombraron miembro de la Real Cámara, como disciplinado que era, asistía a las sesiones, se sentaba en su escaño y escuchaba. Un día por fin pidió la palabra. Un murmullo recorrió la Cámara. Newton, el gran Newton iba a hablar. Se hizo un silencio sepulcral. Newton se levantó.

- Por favor, alguien puede tener la bondad de cerrar aquella ventana, porque pasa corriente.

Se sentó y fue su primera y última intervención.

Siguiendo con los flujos de corriente y los frioleros, sin duda el científico más friolero fue el barón Jean Baptiste Joseph Fourier (1768-1830). Era de un friolero que espantaba, tanto es así que, en pleno verano, andaba con gabán y con las estufas de su casa a todo gas o toda leña, siendo el terror de sus invitados que sabían que entrar en casa del Barón era peor que un baño turco. Precisamente, una de las mayores contribuciones de Fourier a la Física fue el análisis de la propagación del calor, en que introdujo su famoso desarrollo en serie de senos y cosenos, además de los estudios sobre estadística y análisis de funciones. Al parecer su problema derivaba de una enfermedad que contrajo en la expedición napoleónica a Egipto, aunque también he leído que fue antes el huevo que la gallina y que precisamente solicitó participar en la expedición "buscando el calorcito".

Iba a cerrar por hoy, pero me doy cuenta de que no ha aparecido uno de mis protagonistas habituales, Werner Heisenberg. Ya mayor y enfermo de cáncer decía: 
- Pronto voy a morir y como no he sido malo del todo, espero ir al cielo -Werner Heisenberg era creyente y no se avergonzaba de ello-, cuando llegue le pediré al Padre Eterno que me explique tres cosas: La Relatividad, la Mecánica Cuántica y la Mecánica de los Fluidos. Las dos primeras espero que me las sepa explicar.

Y como con fluidos acabo, otro día empezaré por los Bernouilli, que tienen tela. 